\title{
Psychometric properties of a Thai version internet addiction test
}

\author{
Adam Neelapaijit, Manee Pinyopornpanish, Sutapat Simcharoen, Pimolpun Kuntawong, \\ Nahathai Wongpakaran and Tinakon Wongpakaran * (D)
}

\begin{abstract}
Objective: The aim was to assess the reliability and validity of a Thai version internet addiction test.

Results: Cronbach's alpha for the Thai version of the internet addiction test was 0.89. A three-factor model showed the best fit with the data for the whole sample, whereas the hypothesized six-factor model, as well as a unidimensional model of the internet addiction test, failed to demonstrate acceptable fit with the data. Three factors, namely functional impairment, withdrawal symptoms and loss of control, exhibited Cronbach's alphas of 0.81, 0.81, and 0.70, respectively. Item 4, 'to form new relationships with online users', yielded the lowest loading coefficient of all items. Positive correlations between the internet addiction test and UCLA loneliness scores were found. The Thai version of the internet addiction test was considered reliable and valid, and has sufficient unidimensionality to calculate for total score in screening for excessive internet use.
\end{abstract}

Keywords: Internet, IAT, Loneliness, Psychometrics, Validity, Thai

\section{Introduction}

Internet addiction has been specified as pathological internet use, compulsive Internet use and problematic Internet use $[1,2]$. The inability to control Internet use impacts the body's immune system, and work, social and academic performance [3-5]. Factors associated with Internet addiction include social isolation, low selfesteem, depression, personality traits, and interpersonal problems [6-8]. Despite the fact that problems arise from pathological use of the Internet, Internet addiction has not yet been included in the Diagnostic and Statistical Manual of Mental Disorders (DSM-5). The only behavioral addiction included in the latest version of the DSM is gambling disorder, which was included in a section recommending further study.

The prevalence of Internet addiction is estimated to be between 5.2 and $80.5 \%$ [9]. In Thailand, internet addiction has been investigated in both college and clinical

${ }^{*}$ Correspondence: Tinakon.w@cmu.ac.th

Department of Psychiatry, Faculty of Medicine, Chiang Mai University, 110

Intawaroros Rd., T. Sriphum, A. Muang, Chiang Mai 50200, Thailand settings, and $24.4 \%$ of participants were found to exhibit a low level of internet addiction [10,11].

A number of instruments have been used to assess Internet addiction. The internet addiction test (IAT), developed by Young, is one of the most common tools and has been widely tested for its psychometric properties [12-16]. The IAT has demonstrated clinical relevance to addictive properties such as problems with time management, loss of control, impact on relationships [17]. The IAT has been shown to have excellent reliability, as assessed by internal consistency using Cronbach's alpha, and good test-retest reliability [18]. Two studies from Korea, and one from Germany reported 2-week correlations ranging from 0.77 to 0.85 [18-20].

The validity of the test has been examined and reported in several languages including French [21], Italian [22], Portuguese [23], Spanish [16], German [24], Chinese [14], Malay [25], and Vietnamese [26]. The number of factors discovered through related research is inconsistent, ranging from 1 to 6 factors, depending on the sample and study setting employed [21, 22, 25, 27, 28]. Young proposed the six-factor model in the early stages of investigation of the IAT [28]. However, in a subsequent 
study with a larger sample size, the three-factor model was revealed to fit the data better [29]. Recent studies have found that two factors can adequately represent the model $[12,22]$. The item commonly found to be misfitted is item 4, 'to form new relationships with online users', while other misfit items vary from study to study $[18,22]$.

While the IAT is increasingly being used to examine the Thai population, the Thai version of the IAT has never been examined for validity and reliability. The purpose of the present paper is to investigate the psychometric properties of the Thai version of the IAT in terms of factor structure, internal consistency, and possible misfit item(s) with other studies, as well as examining concurrent validity with other measurements.

\section{Main text \\ Methods \\ Participants}

First to sixth-year medical students from Chiang Mai University, Thailand, participated in this study by means of convenience sampling in 2015. Of 324 participants, $56.8 \%$ were female. The mean age was 20.88 (SD 1.8). All completed demographic data questionnaires and answered questions regarding their internet use using the IAT and the UCLA loneliness scale. The average time spent on the internet daily was $4.9 \mathrm{~h}(\mathrm{SD}=2.7)$, and 6.9 days per week. According to Young's addiction level, $63.3 \%$, none; $30.9 \%$, mild; $5.2 \%$, moderate; and $0.6 \%$, severe.

\section{Measurements}

The Thai version of the IAT: The IAT, developed by Young [17], is a 20-item self-report instrument in which respondents rate their tendency for addiction to the internet using a five-point scale, ranging from 1 (rarely) to 5 (always). The IAT total score is the sum of the ratings given by the examinee in response to the 20 items. The higher the score, the higher the level of severity of internet compulsivity and addiction. Total scores of more than 30 are considered to indicate addiction. We obtained permission from Dr. Kimberly Young to translate the IAT and use it in our research study. The forward and backward translation process was done. The study sample had a Cronbach's alpha of 0.89 .

UCLA loneliness scale: The UCLA loneliness scale is an assessment tool used to screen and assess the severity of loneliness. It consists of 20 items asking respondents how often they experienced feelings of loneliness during the past week. Four-point responses to each item range from 0 ('not at all') to 3 ('almost daily'). The Thai version demonstrated good reliability and validity [30]. The UCLA loneliness scale was used to evaluate the convergent validity of the Thai version of the IAT because a correlation between loneliness and internet addiction has been previously reported [31, 32].

\section{Statistical analysis}

Descriptive statistics was used for demographic data as well as data screening analysis for factor analysis. Item responses exhibited skewness and kurtosis $(> \pm 2)$ [33]. Exploratory factor analysis (EFA) using ordered categorical (ordinal) response was performed. For parameter estimation, as data were ordinals, robust weighted least square means and variance adjusted (WLSMV) were employed for estimators [34]. Confirmatory factor analysis (CFA) was used to test Young's hypothesized six-factor model [28].

Regarding fit indexes, in the Comparative Fit Index (CFI) and Tucker-Lewis Index (TLI), a value $>0.90$ indicates reasonable fit, and a value $>0.95$ indicates good model fit; a weighted root-mean-square residual (WRMR) lower than 0.9, a root-mean-square error of approximation (RMSEA) of $\leq 0.06$, and a standardized root mean square residual (SRMR) of $<0.08$ indicate a reasonable fit [35-37]. In addition, the $\chi^{2}$ statistic has been used to test the goodness of model fit if the ratio $\chi^{2} / d f<3$ [33]. Missing data $(0.5 \%)$ were replaced by series of means. Modification indices were added to the model after the initial analysis, and CFA was carried out using Mplus 7.4 [38]. Pearson's correlation analyses were used to determine concurrent validity, and Cronbach's alpha was calculated to assess internal consistency.

\section{Results}

The objective of the analyses was to examine the internal consistency and the factor structure of the translated Thai version of the IAT.

Table 1 shows the mean and SD of each item. Cronbach's alpha for all items was 0.89. The Corrected ItemTotal Correlations were $>0.4$, except for items 4 and 7 , for which the alpha was estimated to be higher when either of these two items was deleted.

The eigenvalues for the sample correlation matrix (EFA) were 7.811, 1.723, and 1.269. The factor loading coefficients are set out in detail in Table 2. The scree plot suggested three factors due to the manner in which the slope levels off. The scree plot according to eigenvalues (Additional file 1: Figure S1) determined the number of these three factors (components).

Cross-loadings $(\geq 0.4)$ were found in all items except for items 6,8 and 12 . Item 4 had the lowest loading coefficient (0.356), followed by item 7 (0.439) on the one-factor model. Factor 1 covered items describing performance problems at school or at work, and relationship problems due to excessive Internet use. Factor 2, which dealt with 'withdrawal symptoms', involved depression, 
Table 1 Mean, SD, Cronbach's alpha, and item-total correlation among IAT items

\begin{tabular}{llllll}
\hline & Mean & SD & $\begin{array}{l}\text { Corrected item-total } \\
\text { correlation }\end{array}$ & $\begin{array}{l}\text { Squared multiple } \\
\text { correlation }\end{array}$ & $\begin{array}{l}\text { Cronbach's alpha } \\
\text { if item deleted }\end{array}$ \\
\hline 1. Stay online longer than intended & 3.25 & 0.996 & 0.438 & 0.343 & 0.884 \\
2. Neglect household chores & 2.41 & 1.149 & 0.496 & 0.407 & 0.883 \\
3. Prefer excitement of internet & 1.81 & 1.051 & 0.509 & 0.328 & 0.882 \\
4. New relationships with online users & 1.59 & 1.188 & 0.313 & 0.179 & 0.888 \\
5. Others complain to you & 1.2 & 1.052 & 0.553 & 0.361 & 0.881 \\
6. Your work suffers & 1.25 & 1.134 & 0.542 & 0.235 & 0.881 \\
7. Check email before something else & 1.03 & 1.23 & 0.363 & 0.461 & 0.887 \\
8. Your job performance suffers & 1.4 & 1.054 & 0.578 & 0.351 & 0.88 \\
9. Become defensive when asked & 0.74 & 0.918 & 0.496 & 0.345 & 0.882 \\
10. Block out disturbing thoughts & 1.09 & 1.128 & 0.536 & 0.417 & 0.881 \\
11. Find yourself anticipating & 1.56 & 1.104 & 0.563 & 0.357 & 0.881 \\
12. Fear life without the internet & 1.72 & 1.344 & 0.439 & 0.372 & 0.885 \\
13. Snap if someone bothers & 0.46 & 0.808 & 0.52 & 0.353 & 0.882 \\
14. Lose sleep due to being online & 2.24 & 1.289 & 0.522 & 0.444 & 0.882 \\
15. Feel preoccupied with the internet & 0.67 & 0.964 & 0.56 & 0.382 & 0.881 \\
16. "Just a few more minutes" & 1.73 & 1.444 & 0.482 & 0.479 & 0.884 \\
17. Try to cut down the amount of time & 1.78 & 1.231 & 0.583 & 0.377 & 0.317 \\
18. Try to hide how long & 0.67 & 0.946 & 0.56 & 0.42 & 0.88 \\
19. Prefer spending time online & 1.49 & 1.235 & 0.505 & 0.528 & 0.881 \\
20. Feel depressed, when off-line & 0.75 & 1.03 & 0.882 &
\end{tabular}

irritability, and fear when not using the Internet. Factor 3, 'loss of control', contained items about failed attempts to cut down on Internet use. The correlation coefficients between Factors 1 and 2, 1 and 3 and 2 and 3 were 0.594 $(\mathrm{p}<.05) ; 0.175(\mathrm{p}>.05)$ and $0.014(\mathrm{p}>.05)$, respectively. The Cronbach's alphas for the factors were $0.70-0.81$, and 0.89 for all items. The total scores of the Thai version of the IAT were significantly correlated with the UCLA loneliness scale $(r=0.293, p<.001)$. Level of loneliness, which is related to Internet addiction, was also significantly correlated, which provides strong support for the concurrent validity of the Thai version of the IAT.

Table 3 shows the goodness of fit of various models. The unidimensional models demonstrated poor fit, whereas the hypothesized six-factor models yielded better fit but were still unacceptable. The three-factor model provided the best fit to the data, with CFI and TLI values exceeding 0.95 and an RMSEA of less than 0.06 .

\section{Discussion}

This study found that the Thai version of the IAT demonstrates similar satisfactory results to the previous study, particularly among the medical student sample. The corrected $\mathrm{R}$ squared of item 4 ('forming new relationships with fellow on-line users') presented the lowest value (0.179) of all items, which endorsed the findings of related studies in different cultures [12, 18, 22]. We hypothesized that this item may reflect the pathological behaviors associated with excessive Internet use less accurately than the remainder of the items.

In exploring factor structure, our results extracted three factors, whereas other researchers have proposed various factor solutions, ranging from 1 to 6 . The first analysis of the IAT by two studies yielded a six factorsolution $[28,39]$. Notably, both studies analyzed the test using a relatively low sample size (a sample of 86 in the former and 115 in the latter study). When repeated with a larger sample size, the number of factors was generally reduced to $2-3[20,22,40]$. This difference was likely due to the differences among the samples, which variously comprised college students and clinical samples, and whose cultural backgrounds differed.

Our findings differed from that of other research conducted among medical students. A Malay sample identified a five-factor model of the IAT [25], whereas a three-factor solution was found among Greek, Persian, and Pakistani samples [41-43]. Except for Malaysia, samples comprising medical students provided the same three-factor solution in various studies. Items within each factor differed due to the differences between the various samples' characteristics, environments, and cultural and religious backgrounds.

Because no hypothesized model was proposed by Young in the original version of the IAT, attempts have 
Table 2 Cronbach's alpha and loading coefficients of one-factor and 3-factor solutions of the Thai version of the IAT

\begin{tabular}{|c|c|c|c|c|}
\hline \multirow[t]{2}{*}{ IAT item } & \multirow[t]{2}{*}{ One-factor } & \multicolumn{3}{|l|}{ Component } \\
\hline & & F1_functional impairment & F2_withdrawal symptom & F3_loss control \\
\hline 8. Your job performance suffers & 0.678 & 0.743 & 0.449 & 0.283 \\
\hline 6. Your work suffers & 0.643 & 0.717 & 0.391 & 0.330 \\
\hline 5. Others complain to you & 0.628 & 0.658 & 0.497 & 0.099 \\
\hline 2. Neglect household chores & 0.629 & 0.650 & 0.359 & 0.419 \\
\hline 9. Become defensive when asked & 0.598 & 0.630 & 0.531 & -0.087 \\
\hline 10. Block out disturbing thoughts & 0.628 & 0.619 & 0.546 & 0.056 \\
\hline 1. Stay online longer than intended & 0.538 & 0.549 & 0.282 & 0.468 \\
\hline 3. Prefer excitement of internet & 0.605 & 0.546 & 0.496 & 0.240 \\
\hline 7. Check email before something else & 0.439 & 0.472 & 0.335 & 0.079 \\
\hline 15. Feel preoccupied with the internet & 0.694 & 0.446 & 0.778 & 0.080 \\
\hline 20. Feel depressed, when off-line & 0.652 & 0.461 & 0.750 & -0.070 \\
\hline 13. Snap if someone bothers you & 0.655 & 0.474 & 0.719 & 0.003 \\
\hline 11. Find yourself anticipating & 0.652 & 0.436 & 0.711 & 0.114 \\
\hline 18. Try to hide length of internet use & 0.668 & 0.538 & 0.666 & 0.075 \\
\hline 12. Fear life without the internet & 0.520 & 0.297 & 0.647 & -0.043 \\
\hline 19. Prefer spending time online & 0.583 & 0.499 & 0.562 & 0.052 \\
\hline 14. Lose sleep due to being online & 0.608 & 0.436 & 0.538 & 0.365 \\
\hline 4. New relationships with online users & 0.359 & 0.364 & 0.390 & -0.198 \\
\hline 17. Try to cut down the amount of time & 0.700 & 0.513 & 0.535 & 0.599 \\
\hline 16. "Just a few more minutes" & 0.589 & 0.364 & 0.472 & 0.592 \\
\hline Cronbach's alpha & 0.89 & 0.81 & 0.81 & 0.70 \\
\hline
\end{tabular}

Table 3 Comparison of fit indices among three proposed models

\begin{tabular}{llllllllr}
\hline Fit indices & $\mathbf{X}^{\mathbf{2}}$ & Df & $\boldsymbol{p}$ value & Chi/df & RMSEA & CFI & TLI & SRMR \\
\hline Hypothesized-6 factor & 521.019 & 155 & 0.000 & 3.361 & $0.085(0.077-0.094)$ & 0.903 & 0.881 & 1.254 \\
Three-factor & 248.516 & 133 & 0.000 & 1.869 & $0.052(0.042-0.062)$ & 0.969 & 0.956 & 0.044 \\
One-factor & 565.112 & 170 & 0.000 & 3.324 & $0.085(0.077-0.092)$ & 0.895 & 0.883 & 0.079 \\
\hline
\end{tabular}

df degrees of freedom, RMSEA root-mean-square error of approximation, CFI comparative fit index, TLITucker-Lewis index, SRMR standardized root mean square residual

been made to design more valid and reliable items in a newer version. In revising the IAT, many investigators have suggested removing the item(s) with low loading coefficients on designated factors or reducing problems with cross-loadings on other factors. However, these suggestions may be of limited relevance to the studied samples, and cannot necessarily be applied to other studies. One important property of the scale is its unidimensionality, which requires creating a cut-off score to define various levels of the problem. The unidimensionality of the model should be warranted to determine the legitimacy of summarizing the scale in a single score $[44,45]$. Some investigators have suggested that, when the ratio of firstto-second eigenvalues is greater than four, the model can be considered unidimensional $[46,47]$.
To date, we have found only two studies identifying the IAT as a unidimensional model [13, 21]; one seems to show that it has sufficient unidimensionality [27]. The remainder of the existing studies found two or more factor solutions, including the present study. However, using the above criteria, the Thai version of the IAT showed sufficient unidimensionality. In addition, in the revising process, culturally biased items and differential item functioning due to sex should be identified to make the test more capable of being compared across cultures.

In conclusion, the Thai version of the IAT was shown to have good reliability and concurrent validity, as demonstrated by a significant correlation between the UCLA loneliness scale and the IAT. This relationship reflects some convergent validity because loneliness and Internet 
addiction were found to be correlated, especially among university or college students [31, 32]. A three-factor model fits the data well; in addition, it has sufficient unidimensionality to allow the total score to be used to screen for excessive Internet use.

\section{Limitations}

This study has some limitations. First, even though the sample represents all levels of medical student, recruitment was not randomized. Second, test-retest reliability was not conducted to ensure temporal stability. Third, medical students may not be representative of the general population, so further examination of the validity and reliability of the test should be conducted in other populations. Further exploration in relation to shortening the scale to make it more unidimensional is encouraged.

\section{Additional file}

Additional file 1: Figure S1. Eigenvalues among participants with Internet addiction. From the third component on, the line is almost flat, indicating each successive factor is accounting for smaller and smaller amounts of the total variance.

\section{Abbreviations}

CFA: confirmatory factor analysis; CFI: Comparative Fit Index; DSM-5: diagnostic and statistical manual of mental disorders; EFA: exploratory factor analysis; IAT: internet addiction test; RMSEA: root-mean-square error of approximation; SRMR: standardized root mean square residual; TLI: Tucker-Lewis Index; UCLA: University of California Los Angeles; WLSMV: weighted least square means and variance adjusted; WRMR: weighted root-mean-square residual.

\section{Authors' contributions}

AN, MP, NW and TW conceived the study. AN, MP, NW and TW designed the study. SS and PK collected and cleansed data. NW and TW analyzed the data. AN, MP, NW and TW wrote the initial draft. AN, MP, SS, PK, NW and TW revised the draft manuscript. All authors read and approved the final manuscript.

\section{Acknowledgements}

The authors thank all participating medical students, who made this study successful.

\section{Competing interests}

The authors declare that they have no competing interests.

\section{Availability of data and materials}

The datasets generated and/or analyzed during the current study are available from the authors on reasonable request.

\section{Consent for publication}

Not applicable.

\section{Ethics approval and consent to participate}

Ethical approval for this study was obtained from the Ethics Review Committee, Faculty of Medicine, Chiang Mai University (Ethics Approval Number REC-25580428-04268). Informed written consent was obtained from all participants.

\section{Funding}

Not applicable.

\section{Publisher's Note}

Springer Nature remains neutral with regard to jurisdictional claims in published maps and institutional affiliations.

Received: 21 November 2017 Accepted: 17 January 2018

Published online: 24 January 2018

\section{References}

1. Greenfield DN. Psychological characteristics of compulsive internet use: a preliminary analysis. Cyberpsychol Behav. 1999;2:403-12.

2. Shapira NA, Goldsmith TD, Keck PE, Khosla UM, McElroy SL. Psychiatric features of individuals with problematic internet use. J Affect Disord. 2000;57:267-72.

3. Engelberg E, Sjöberg L. Internet use, social skills, and adjustment. Cyberpsychol Behav. 2004;7:41-7.

4. Leung L, Lee PSN. Impact of internet literacy, internet addiction symptoms, and internet activities on academic performance. Soc Sci Comput Rev. 2012;30:403-18.

5. Reed P, Vile R, Osborne LA, Romano M, Truzoli R. Problematic internet usage and immune function. PLOS ONE. 2015;10:e0134538.

6. Zamani BE, Abedini Y, Kheradmand A. Internet addiction based on personality characteristics of high school students in Kerman, Iran. Addict Health. 2011;3:85-91.

7. Senormancı O, Konkan R, Güçlü O, Senormancı G. Depression, loneliness, anger behaviours and interpersonal relationship styles in male patients admitted to internet addiction outpatient clinic in Turkey. Psychiatr Danub. 2014;26:39-45.

8. Seo M, Kang HS, Yom YH. Internet addiction and interpersonal problems in Korean adolescents. Comput Inform Nurs. 2009;27:226-33.

9. Zhang MWB, Lim RBC, Lee C, Ho RCM. Prevalence of internet addiction in medical students: a meta-analysis. Acad Psychiatry. 2017. https://doi. org/10.1007/s40596-017-0794-1.

10. Kaewpradub N, Kiatrungrit K, Hongsanguansri S, Pavasuthipaisit C. Association among internet usage, body image and eating behaviors of secondary school students. Shanghai Arch Psychiatry. 2017;29:208-17.

11. Boonvisudhi T, Kuladee S. Association between Internet addiction and depression in Thai medical students at Faculty of Medicine, Ramathibodi Hospital. PLOS ONE. 2017;12:e0174209.

12. Jelenchick LA, Becker T, Moreno MA. Assessing the psychometric properties of the internet addiction test (IAT) in US college students. Psychiatry Res. 2012;196:296-301.

13. Faraci P, Craparo G, Messina R, Severino S. internet addiction test (IAT): which is the best factorial solution? J Med Internet Res. 2013;9:e225.

14. Lai C-M, Mak K-K, Watanabe H, Ang RP, Pang JS, Ho RCM. Psychometric properties of the internet addiction test in Chinese adolescents. J Pediatr Psychol. 2013;38:794-807.

15. Boysan M, Kuss DJ, Barut Y, Ayköse N, Güleç M, Özdemir O. Psychometric properties of the Turkish version of the internet addiction test (IAT). Addict Behav. 2017;64:247-52.

16. Fernández-Villa T, Molina AJ, García-Martín M, Llorca J, Delgado-Rodríguez M, Martín V. Validation and psychometric analysis of the internet addiction test in Spanish among college students. BMC Public Health. 2015;15:953.

17. Young K. Internet addiction: the emergence of a new clinical disorder. CyberPsychol Behav. 1998;1:237-44.

18. Lee $K$, Lee H-K, Gyeong H, Yu B, Song Y-M, Kim D. Reliability and validity of the Korean version of the internet addiction test among college students. J Korean Med Sci. 2013;28:763-8.

19. Chang-Kook Y, Byeong-Moo C, Matthew B, Jeong-Hyeong L, Jin-Seok C. SCL-90-R and 16PF profiles of senior high school students with excessive internet use. Canadian J Psychiatry. 2005;50:407-14.

20. Barke A, Nyenhuis N, Kröner-Herwig B. The German version of the internet addiction test: a validation study. Cyberpsychol Behav Soc Netw. 2012;15:534-42.

21. Khazaal Y, Billieux J, Thorens G, Khan R, Louati Y, Scarlatti E, Theintz F, Lederrey J, Linden M, Zullino D. French validation of the internet addiction test. Cyberpsychol Behav. 2008;11:703-6. 
22. Servidio R. Assessing the psychometric properties of the internet addiction test: a study on a sample of Italian university students. Comput Hum Behav. 2017;68:17-29.

23. Pontes HM, Patrão IM, Griffiths MD. Portuguese validation of the internet addiction test: an empirical study. J Behav Addict. 2014;3:107-14.

24. Wartberg L, Petersen KU, Kammerl R, Rosenkranz M, Thomasius R. Psychometric validation of a German version of the compulsive internet use scale. Cyberpsychol Behav Soc Netw. 2014;17:99-103.

25. Chong Guan N, Mohammed Isa S, Hanim Hashim A, Pillai S, Kaur Harbajan Singh M. Validity of the Malay Version of the internet addiction test: a study on a group of medical students in Malaysia. 2012.

26. Tran BX, Mai HT, Nguyen LH, Nguyen CT, Latkin CA, Zhang MWB, Ho RCM. Vietnamese validation of the short version of internet addiction test. Addict Behav Rep. 2017;6:45-50.

27. Korkeila J, Kaarlas S, Jääskeläinen M, Vahlberg T, Taiminen T. Attached to the web-harmful use of the Internet and its correlates. Eur Psychiatr. 2010;25:236-41.

28. Widyanto L, McMurran M. The psychometric properties of the internet addiction test. Cyberpsychol Behav. 2004;7:443-50

29. Widyanto L, Griffiths MD, Brunsden V. A psychometric comparison of the internet addiction test, the internet-related problem scale, and selfdiagnosis. Cyberpsychol Behav Soc Netw. 2010;14:141-9.

30. Wongpakaran T, Wongpakaran N. A short version of the revised 'experience of close relationships questionnaire': investigating non-clinical and clinical samples. Clin Pract Epidemiol Ment Health. 2012;8:36-42.

31. Koyuncu T, Unsal A, Arslantas D. Assessment of internet addiction and loneliness in secondary and high school students. J Pak Med Assoc. 2014;64:998-1002.

32. Li W, Zhang W, Xiao L, Nie J. The association of Internet addiction symptoms with impulsiveness, loneliness, novelty seeking and behaviora inhibition system among adults with attention-deficit/hyperactivity disorder (ADHD). Psychiatry Res. 2016;243:357-64.

33. Kline RB. Principles and practice of structural equation modeling. New York: Guilford; 1998

34. Li CH. Confirmatory factor analysis with ordinal data: comparing robust maximum likelihood and diagonally weighted least squares. Behav Res Methods. 2016;48:936-49.

35. Evaluating model fit. In: Hu L, Bentler PM editors. Structural equation modeling: concepts, issues and applications. California: Sage; 1995.
36. Hu L, Bentler PM. Fit indices in covariance structure modeling: sensitivity to under parameterized model misspecification. Psychol Methods. 1998;3:424-53.

37. Hu L, Bentler PM. Cut off criteria for fit indexes in covariance structure analysis: conventional criteria versus new alternatives. Struct Equ Model. 1999;6:1-55.

38. Muthen LK, Muthen BO. Mplus user's guide, 7th edition. Los Angeles: Muthén \& Muthén. 2015:1998-2015.

39. Conti MA, Jardim AP, Hearst N, Cordás TA, Tavares H. Abreu CNd: avaliação da equivalência semântica e consistência interna de uma versão em português do internet addiction test (IAT). Arch Clin Psychiatr. 2012;39:106-10.

40. Chang M, Law S. Factor structure for Young's internet addiction test: a confirmatory study. Comput Human Behav. 2008;24:2597-619.

41. Tsimtsiou Z, Haidich AB, Kokkali S, Dardavesis T, Young KS, Arvanitidou M. Greek version of the internet addiction test: a validation study. Psychiatr Q. 2014;85:187-95.

42. Mohammadsalehi N, Mohammadbeigi A, Jadidi R, Anbari Z, Ghaderi E, Akbari M. Psychometric properties of the persian language version of yang internet addiction questionnaire: an explanatory factor analysis. Int J High Risk Behav Addict. 2015;4:e21560.

43. Waqas A, Farooq F, Raza M, Javed ST, Khan S, Ghumman ME, Naveed S, Haddad M. Validation of the internet addiction test in students at a Pakistani Medical and Dental School. Psychiatr Q. 2017. https://doi. org/10.1007/s11126-017-9528-5.

44. Nunnally JC, Bernstein IH. Psychometric theory. 3rd ed. New York: McGraw-Hill, Inc: 1994.

45. Smith EV. Detecting and evaluating the impact of multidimensionality using item fit statistics and principal component analysis of residuals. J Appl Meas. 2002;3:205-31.

46. Slocum-Gori SL, Zumbo BD: Assessing the unidimensionality of psychological scales: using multiple criteria from factor analysis. Soc Indic Res. 2011:102:443-61.

47. Reeve BB, Hays RD, Bjorner JB, Cook KF, Crane PK, Teresi JA, Thissen D, Revicki DA, Weiss DJ, Hambleton RK, et al. Psychometric evaluation and calibration of health-related quality of life item banks: plans for the patient-reported outcomes measurement information system (PROMIS). Med Care. 2007:45:S22-31.

\section{Submit your next manuscript to BioMed Central and we will help you at every step:}

- We accept pre-submission inquiries

- Our selector tool helps you to find the most relevant journal

- We provide round the clock customer support

- Convenient online submission

- Thorough peer review

- Inclusion in PubMed and all major indexing services

- Maximum visibility for your research

Submit your manuscript at www.biomedcentral com/submit
O Biomed Central 